\title{
Emerging roles of protein kinase CK2 in abscisic acid signaling
}

\author{
Belmiro Vilela, Montserrat Pagès and Marta Riera* \\ Centre for Research in Agricultural Genomics (CRAG), CSIC-IRTA-UAB-UB Consortium, Campus UAB, Barcelona, Spain
}

The phytohormone abscisic acid (ABA) regulates many aspects of plant growth and development as well as responses to multiple stresses. Post-translational modifications such as phosphorylation or ubiquitination have pivotal roles in the regulation of ABA signaling. In addition to the positive regulator sucrose non-fermenting-1 related protein kinase 2 (SnRK2), the relevance of the role of other protein kinases, such as CK2, has been recently highlighted. We have recently established that CK2 phosphorylates the maize ortholog of open stomata 1 OST1, ZmOST1, suggesting a role of CK2 phosphorylation in the control of ZmOST1 protein degradation (Vilela et al., 2015). CK2 is a pleiotropic enzyme involved in multiple developmental and stress-responsive pathways. This review summarizes recent advances that taken together suggest a prominent role of protein kinase CK2 in ABA signaling and related processes.

OPEN ACCESS

Edited by:

Sylvain Jeandroz, Agrosup Dijon, France

Reviewed by:

Ingo Dreyer,

Universidad de Talca, Chile

Stephane Bourque,

Institut national de la recherche

agronomique, France

*Correspondence:

Marta Riera

marta.riera@cragenomica.es

Specialty section:

This article was submitted to

Plant Physiology,

a section of the journal

Frontiers in Plant Science

Received: 22 September 2015

Accepted: 22 October 2015

Published: 03 November 2015

Citation:

Vilela B, Pagès M and Riera M (2015) Emerging roles of protein kinase $C K 2$

in abscisic acid signaling.

Front. Plant Sci. 6:966.

doi: $10.3389 /$ fpls.2015.00966
Keywords: protein kinase CK2, ABA signaling, proteasome degradation, circadian clock, post-translational modifications

\section{INTRODUCTION}

The phytohormone abscisic acid (ABA) plays a central role in plant development and responses to abiotic stress (Leung and Giraudat, 1998; Finkelstein et al., 2002). Water stress conditions induce the accumulation of ABA levels in guard cells and this increase promotes the closing of stomata in order to reduce transpiration and water loss (Schroeder et al., 2001). The molecular mechanism of ABA action is now well-established in Arabidopsis (Cutler et al., 2010; Kim et al., 2010; Klingler et al., 2010; Raghavendra et al., 2010; Umezawa et al., 2010; Zhang et al., 2015). ABA triggers downstream responses by binding to the cytosolic receptors pyrabactin resistance/pyrabactin-like/regulatory component of $\mathrm{ABA}$ receptor (PYR/PYL/RCAR), which then sequester the negative regulators clade $\mathrm{A}$ type $2 \mathrm{C}$ protein phosphatases (PP2C), allowing the activation of Group III Sucrose non-fermenting1 related protein kinases 2 (SnRK2; Ma et al., 2009; Park et al., 2009). These three protein types are necessary and sufficient to mediate an ABA triggered model signaling cascade in vitro (Fujii et al., 2009). Recent advances engineering ABA receptors using agrochemicals open new possibilities for crop improvement (Park et al., 2015).

Reversible protein phosphorylation is therefore a key protein modification involved in ABA signaling and it allows for the rapid regulation of protein function. In addition to the central role of Group III SnRK2s, multiple kinases have been implicated in ABA signaling. Calcium-dependent protein kinases (CDPKs) function as calcium sensors and are hub regulators of $\mathrm{Ca}^{2+}$-mediated immune and stress responses (Mori et al., 2006; Boudsocq and Sheen, 2013). CBL-interacting protein kinases (CIPKs), another family of kinases involved in calcium signaling, regulate potassium transport processes in roots and in stomatal guard cells (Cheong et al., 2007). Moreover, mitogen activated protein kinases (MAPKs) are induced by ABA to elicit a stress response (Danquah et al., 2015). 
There is growing amount of data linking protein kinase CK2 to ABA signaling and abiotic stress responses, as shown in this review. CK2 is an evolutionary conserved Ser/Thr kinase found in all eukaryotes. The CK2 holoenzyme is a heterotetramer composed by two types of subunits, two catalytic (CK2 $\alpha)$ and two regulatory (CK2 $\beta$; Litchfield, 2003). Unlike animals, in plants both kinds of subunits are encoded by multigenic families (VelezBermudez et al., 2011). Plant CK2 is a pleiotropic enzyme involved in relevant processes such as plant growth and development, lightregulated gene expression, circadian rhythm, hormone responses, cell-cycle regulation, flowering time, DNA repair or responses to biotic and abiotic stress, among others (Riera et al., 2013; Mulekar and Huq, 2014).

\section{ROLE OF PROTEIN KINASE CK2 IN ABA SIGNALING}

Since CK2 is essential for plant viability and the depletion of $\mathrm{CK} 2 \alpha$ is lethal, as previously demonstrated in yeast (Padmanabha et al., 1990), plant genetic approaches involving CK2 have been difficult. The first Arabidopsis CK $2 \alpha$ antisense plants produced confirmed the role of $\mathrm{CK} 2$ in light-regulated gene expression and plant growth (Lee et al., 1999). In recent years, several transgenic lines for $\mathrm{CK} 2 \alpha$ have been generated. An inducible dominant-negative for CK2 $\alpha$ plants evidenced that CK2 control chloroplast development, cotyledon expansion, root and shoot growth, as well as altered cell division, cell expansion and auxin transport (Moreno-Romero et al., 2008; Marquès-Bueno et al., 2011). Arabidopsis mutated for all three nuclear CK2 $\alpha$ subunits $(\alpha 1 \alpha 2 \alpha 3)$ or doubly mutated in all possible combinations, show a significant decrease of CK2 activity, and a clear phenotype of late flowering. This indicates that that CK2 $\alpha$ subunits influence the circadian clock period of oscillation (Lu et al., 2011). Moreover, CK2 $\alpha$ knockout lines display altered developmental and stress responsive pathways with a marked hyposensitivity to ABA and high salt when tested by the criteria of seed germination and cotyledon greening (Mulekar et al., 2012).

Chloroplastic isoforms of CK $2 \alpha(\mathrm{cpCK} 2 \alpha)$ have been identified in most higher plants (Turkeri et al., 2012; Vélez-Bermúdez et al., 2015). Different phosphoproteomic approaches in Arabidopsis demonstrate the prominent role of cpCK2 for phosphorylation in these organelles (Reiland et al., 2009; Schonberg et al., 2014). ABA affects the transcription of most chloroplastic genes (Yamburenko et al., 2013, 2015). Mutation of chloroplastic isoform CKA4 in Arabidopsis gives a phenotype of reduced sensitivity to ABA during seed germination and seedling growth, and increased stomatal aperture and leaf water loss (Wang et al., 2014). These effects were attributed to the downregulation of ABAresponsive genes, including OST1, a representative SnRK2 kinase central to ABA signaling. The same work suggests that CK2 is involved in retrograde signaling from chloroplast to nucleus, since the expression levels of the transcription factor $A B I 4$, directly involved in retrograde and $\mathrm{ABA}$ signaling, were reduced in the cka4 mutant under ABA treatment (León et al., 2012). Recent work analyzing CK2A4 RNAi lines in the CK2 $\alpha$ triple mutant background confirmed the importance of this gene in the regulation of $\mathrm{ABA}$ response, lateral root formation and flowering time, in a process that could be regulated by retrograde signaling (Mulekar and Huq, 2015).

Even though more that 300 substrates have been described for mammalian CK2 (Meggio and Pinna, 2003; Bian et al., 2013), the confirmed number of CK2 plant substrates is lower, around 50, as shown in Table 1. Among these substrates, CK2 phosphorylation of maize LEA protein RAB17 has been one of more extensively characterized examples (Plana et al., 1991). LEA proteins/RAB/dehydrins accumulate during embryogenesis and their protein level correlates with increased levels of ABA and acquisition of desiccation tolerance (Galau et al., 1986; Ingram and Bartels, 1996). Previous work performed in our group established that CK2 phosphorylation regulates the intracellular dynamics and subcellular localization of maize RAB17. The phosphodeficient mutant form of RAB17, when overexpressed in transgenic Arabidopsis, leads to a failure of seed germination arrest in osmotic stress conditions (Plana et al., 1991; Riera et al., 2004). The homologs of Rab17 in tomato (TAS14) and in Arabidopsis (ERD14) are also phosphorylated by CK2 (Godoy et al., 1994; Alsheikh et al., 2003). Other dehydrins as TsDHN1, 2 from Thellungiella salsuginea can stabilize the cytoskeleton under stress conditions, in a process that may involve CK2 phosphorylation (Rahman et al., 2011). Recently, ZmLEA5C that enhances tolerance to osmotic and low temperature stresses in transgenic tobacco and yeast has been also described as a CK2 substrate (Liu et al., 2014). Different types of transcription factors are also CK2 substrates, some of them involved in ABA response, as EmBP-2 and ZmBZ-1. These two b-ZIP transcription factors are phosphorylated by $\mathrm{CK} 2$ and this modification alters their DNA binding capacity (Nieva et al., 2005). Also OREB1, a rice $A B R E$ binding factor is phosphorylated by multiple kinases such as SnRK2 and CK2 (Hong et al., 2011). These factors bind to ABRE (ABA Responsive Elements) in the nucleus and activate the transcription of ABA-inducible genes, suggesting that $\mathrm{CK} 2$ regulation of $\mathrm{RAB}$ proteins could involve not only direct phosphorylation but also altered gene expression.

We have recently established the maize ortholog of open stomata 1 OST1 (also known as SnRK2.6 or SnRK2E) as a phosphorylation target of CK2 (Vilela et al., 2015). CK2 phosphorylates ZmOST1 at a cluster of serines in the ABA box with implications on protein levels, kinase activity, and response to abiotic stimuli. Transgenic Arabidopsis plants overexpressing ZmOST1 mutagenized at CK2 phosphorylation sites are more resistant to drought and are hypersensitive to $\mathrm{ABA}$ at the level of stomata.

\section{ABA SIGNALING AND PROTEASOME DEGRADATION}

In addition to phosphorylation, other post-translational modifications such as ubiquitination, and sumoylation play significant roles in regulating ABA signaling (Lyzenga and Stone, 2012). Ubiquitination of the PYR/PYL/RCAR ABA receptors causes their degradation in the absence of ABA (Irigoyen et al., 2014). DDB1-ASSOCIATED1 (DDA1), a protein part of the CULLIN4-RING E3 ubiquitin ligase, binds to PYR8, PYL4 and PYL9 and facilitates their proteasomal degradation, negatively 
TABLE 1 | List of plant CK2 substrates.

\begin{tabular}{|c|c|c|c|c|}
\hline Name & Type & Species & Role & References \\
\hline \multicolumn{5}{|c|}{ Light-signal transduction pathway and circadian clock } \\
\hline AT-1 & DNA binding factor & Pea & $\begin{array}{l}\text { Binds to ATI-box elements in light regulated } \\
\text { promoters }\end{array}$ & Datta and Cashmore (1989) \\
\hline ATBP-1 & DNA binding factor & Pea & $\begin{array}{l}\text { Binds to ATI-box elements in light regulated } \\
\text { promoters }\end{array}$ & Tjaden and Coruzzi (1994) \\
\hline GBF1 & bZIP TF & Arabidopsis & $\begin{array}{l}\text { Binds to G-box elements in light regulated } \\
\text { promoters }\end{array}$ & Klimczak et al. (1995) \\
\hline Opaque2 & bZIP TF & Maize & Circadian clock regulated & Ciceri et al. (1997) \\
\hline CCA1 & Myb-related TF & Arabidopsis & Circadian clock regulator & Sugano et al. (1998) \\
\hline LHY, OsLHY & Myb-related TF & Arabidopsis, Rice & Circadian clock regulator & $\begin{array}{l}\text { Sugano et al. (1998); Ogiso } \\
\text { et al. (2010) }\end{array}$ \\
\hline HY5 & bZIP TF & Arabidopsis & Promotes photomorphogenesis & Hardtke et al. (2000) \\
\hline HFR1 & bHLH TF & Arabidopsis & Promotes photomorphogenesis & Park et al. (2008) \\
\hline PIF1 & Phytochrome interacting factor & Arabidopsis & Represses photomorphogenesis & Bu et al. (2011) \\
\hline \multicolumn{5}{|l|}{ Abiotic and biotic stress } \\
\hline ZmSnRK2/ZmOSTI & Protein kinase & Maize & ABA signaling & Vilela et al. (2015) \\
\hline $\begin{array}{l}\text { Rabl7,ZmLEA5cERD14, } \\
\text { TAS-14 }\end{array}$ & LEA proteins & $\begin{array}{l}\text { Maize, Arabidopsis, } \\
\text { tomato, wheat }\end{array}$ & Stress responsive proteins & $\begin{array}{l}\text { Plana et al. (1991); Liu et al. } \\
\text { (2014); Alsheikh et al. (2003); } \\
\text { Godoy et al. (1994) }\end{array}$ \\
\hline TsDHNI,2 & Dehydrins & Thellungiella salsuginea & Stress responsive proteins & Rahman et al. (2011) \\
\hline EmBP-2/ZmBZ-I & bZIP TF & Maize & $\begin{array}{l}\text { Activates transcription of the abscisic } \\
\text { acid-inducible gene rab28 }\end{array}$ & Nieva et al. (2005) \\
\hline TGA2 & bZIP TF & Arabidopsis & $\begin{array}{l}\text { Binds to promoter of salicilic-induced } \\
\text { genes }\end{array}$ & Kang and Klessig (2005) \\
\hline OREB1 & ABRE binding factor & Rice & Binds to ABRE (ABA responsive Elements) & Hong et al. (2011) \\
\hline p23 & co-chaperone protein & Arabidopsis & Plant response to Salicihc acid & Tosoni et al. (2011) \\
\hline PCS & phytochelatin synthase & Arabidopsis & Synthesis of heavy metal-binding peptides & Wang et al., 2009 \\
\hline \multicolumn{5}{|c|}{ Chromatin associated and nuclear proteins } \\
\hline lamin-like protein & lamina matrix protein & Pea & Nuclear stability, chromatin organization & Li and Roux (1992) \\
\hline MFP1 & coil-coil protein & Tomato Allium cepa & $\begin{array}{l}\text { Structural roles in nuclear matrix and } \\
\text { chloroplast }\end{array}$ & $\begin{array}{l}\text { Meier et al. (1996); } \\
\text { Samaniego et al. (2006) }\end{array}$ \\
\hline NopA64/nopA61 & nucleolin-like phosphoproteins & Allium cepa & Located in nucleolus & de Cárcer et al. (1997) \\
\hline P-proteins & Ribosomal proteins & Maize & Complex with 605 ribosomal subunits & Bailey-Serres et al. (1997) \\
\hline DNA helicase I & DNA helicase I & Pea & DNA transcription & Tuteja et al. (2001) \\
\hline DNA topoisomerase I & DNA topoisomerase I & Pea & DNA transcription & Tuteja et al. (2003) \\
\hline HMGB proteins & High mobility group B proteins & Maize, Arabidopsis & Chromatin associated proteins & Stemmer et al. (2002) \\
\hline SSRP1 & $\begin{array}{l}\text { structure-specific recognition } \\
\text { protein }\end{array}$ & Maize & Chromatin associated proteins & Krohn et al. (2003) \\
\hline elF2ab/3c/4b/5 & elongation initiation factors & $\begin{array}{l}\text { Arabidopsis, maize, } \\
\text { wheat }\end{array}$ & Translation initiation & Dennis and Browning (2009) \\
\hline Histone deacetilase 2B & Histone deacetilase & Arabidopsis & Chromatin remodeling enzyme & Dennis and Browning (2009) \\
\hline \multicolumn{5}{|l|}{ Chloroplast machinery } \\
\hline $\begin{array}{l}\text { Chloroplast } \\
\text { RNPs/28RNP/ } \\
\text { p34/RNP29,33 }\end{array}$ & Ribonucleoproteins & Spinach, Arabidopsis & $\begin{array}{l}\text { RNA binding proteins involved in } \\
\text { chloroplast RNA processing and } \\
\text { stabilization }\end{array}$ & $\begin{array}{l}\text { Kanekatsu et al. (1993, } \\
\text { 1995); Lisitsky and Schuster } \\
\text { (1995); Reiland et al. (2009) }\end{array}$ \\
\hline CP29 & photosystem II subunit & Maize & Light harvesting complex import & Testi et al. (1996) \\
\hline TOC159 & preprotein receptor & Arabidopsis & $\begin{array}{l}\text { Nuclear-encoded chloroplast preproteins } \\
\text { from the cytosol }\end{array}$ & Agne et al. (2010) \\
\hline SIG1/SIG6 & plastid sigma factors & Arabidopsis & $\begin{array}{l}\text { Gene-regulatory proteins for promoter } \\
\text { binding and transcription initiation }\end{array}$ & Schweer et al. (2010) \\
\hline Alb3 & Thylakoid membrane protein & Arabidopsis & Thylakoid biogenesis & Schonberg et al. (2014) \\
\hline \multicolumn{5}{|l|}{ Other } \\
\hline CFOCFI-ATPase & $\begin{array}{l}\text { Chloroplast ATP synthase (b } \\
\text { subunit) }\end{array}$ & Spinach & ATP synthesis & Kanekatsu et al. (1998) \\
\hline $\mathrm{C} 2$ & subunit of the $20 \mathrm{~S}$ proteasome & Rice & $\begin{array}{l}\text { Protein degradation of ubiquitinated } \\
\text { proteins }\end{array}$ & Umeda et al. (1997) \\
\hline gpl00/gp96 & $\begin{array}{l}\text { Glycyrrhizin (GL)-Binding Protein } \\
\text { (gp100) }\end{array}$ & Soybean & $\begin{array}{l}\text { Lipoxygenase that catalyzes the } \\
\text { oxygenation of unsaturated fatty acids }\end{array}$ & Ohtsuki et al. (1994, 1995) \\
\hline$\beta$-Conglycinin $\alpha$ Subunit & $\beta$-Conglycinin $\alpha$ Subunit & Soybean & storage protein & Ralet et al. (1999) \\
\hline calreticulin & Calreticulin & Spinach & $\mathrm{Ca}^{2+}$ binding protein & Baldan et al. (1996) \\
\hline apyrase & apyrase & Pea & ATP hydrolysis & Hsieh et al. (2000) \\
\hline
\end{tabular}


regulating ABA responses. Conversely, ABA protects PYL8 from destabilization by limiting its polyubiquitination by a process that is still unknown. ABA also reduces PYL8 expression after $3 \mathrm{~h}$ of treatment in a process that would facilitate a faster receptor turnover, after the signal is attenuated (Irigoyen et al., 2014). In addition, the turnover of PYL4 and PYR1 in the proximity of the plasma membrane is regulated by the interaction with a single subunit RING-type E3 ubiquitin ligase, RSL1 (Bueso et al., 2014).

Several transcription factors involved in ABA signaling as $\mathrm{ABI}, \mathrm{ABI} 5, \mathrm{ABF}$ ABI4, and ATHB6 can also be regulated by proteasome degradation. The $\mathrm{B} 3$-domain transcription factor ABSCISIC ACID-INSENSITIVE 3 (ABI3), a central regulator in $\mathrm{ABA}$ signaling, is an unstable protein that is polyubiquitinated by an ABI3-interacting protein (AIP2), which contains a RING motif. AIP2 negatively regulates ABA signaling by targeting ABI3 for post-translational destruction (Zhang et al., 2005). During vegetative growth, ABA induces AIP2 expression, tightly regulating $\mathrm{ABI} 3$ turnover while promoting its accumulation during seed maturation. Another example is ABSCISIC ACID INSENSITIVE 5 (ABI5), a member of the basic leucine zipper (bZIP) transcription factor, that plays an important role in controlling ABA dependent postgerminative growth arrest as well as late phases of seed maturation (Finkelstein and Lynch, 2000; Lopez-Molina et al., 2001). The abundance of ABI5 is tightly controlled by the ubiquitin-26S proteasome system. KEEPONGOING (KEG), a RING3-type E3 ubiquitin ligase, negatively regulates ABA signaling by promoting ABI5 ubiquitination and subsequent degradation by the $26 \mathrm{~S}$ proteasome (Liu and Stone, 2010). This process occurs in the cytosol when ABA is absent (Liu and Stone, 2013). In the nucleus, ABI5 stability is regulated by another negative regulator of $\mathrm{ABA}$, a $\mathrm{E} 3$ ubiquitin ligase assembled with $\mathrm{ABA}$ hypersensitive DCAF1 (ABD1; Seo et al., 2014). In addition to ubiquitination, sumoylation of ABI5 is thought to maintain a degradation-resistant inactive pool of ABI5 in the absence of ABA (Miura et al., 2009). An additional class of ABI5-interacting proteins, the AFPs, has also been reported to alter ABI5 stability (Lopez-Molina et al., 2003). Another group of positive effectors in $\mathrm{ABA}$ responses regulated by proteasome degradation is the ABA Binding Factor/ABA-Responsive Element Binding Proteins (ABF/AREB) subfamily of bZIP-type transcription factors. ABF1 and $\mathrm{ABF} 3$ have similar functions to $\mathrm{ABI} 5$ in regulating seed germination and post-germinative growth (Finkelstein et al., 2005). ABF1 and ABF3 are ubiquitylation substrates of KEG and the abundance of both proteins is affected by ABA and the ubiquitin pathway (Chen et al., 2013). The stabilization of ABF1 and $A B F 3$ by $A B A$ is thought to be achieved by phosphorylation by SnRK2 kinases, which in turn promotes the binding of 14-3-3 proteins (Sirichandra et al., 2010). ABSCISIC ACID INSENSITIVE 4 (ABI4), a member of the DREB subfamily A-3 of ERF/AP2 transcription factors, is required for proper $\mathrm{ABA}$ signaling during seed development and germination (Gregorio et al., 2014). Like ABI3 and ABI5, ABI4 is subject to a stringent post-transcriptional regulation that targets the protein to degradation and prevents it from accumulating to high levels. However, unlike ABI3 and ABI5, ABI4 is not stabilized in the presence of ABA (Finkelstein et al., 2011). Finally, the
HD-Zip transcription factor ATHB6 physically interacts with the PP2C phosphatase ABI1 and it has been described as a negative regulator of the ABA signal pathway (Himmelbach et al., 2002). Moreover, ABA negatively regulates ATHB6 protein turnover (Lechner et al., 2011).

Proteosomal degradation in response to ABA is regulated by phosphorylation/dephosphorylation mechanisms (Figure 1A). For instance, ABA promotes the self ubiquitination and degradation of KEG after phosphorylation, a process that could be regulated by the SnRK2 kinases belonging to the core ABA signaling complex (Antoni et al., 2011). Another kinase, Calcineurin B-like Interacting Protein Kinase 26 (CIPK26) interacts with the ABA signaling components $\mathrm{ABI} 1, \mathrm{ABI} 2$, and ABI5. CIPK26 influences the sensitivity of germinating seeds to the inhibitory effects of ABA and is also targeted by KEG for proteasomal degradation (Lyzenga et al., 2013).

Our recent work points toward a role of protein kinase CK2 in control of ZmOST1 protein degradation (Vilela et al., 2015). CK2 phosphorylation enhances ZmOST1 interaction with PP2C phosphatases, probably causing a sustained "off" state of kinase activity, and also primes SnRK2 for protein degradation through the $26 S$ proteasome pathway. Thus, CK2 seems to act in dampening the ABA signal output through its action on ZmOST1 while at the same time inducing ZmOST1 transcription (Figure 1A). This type of regulation would be particularly effective in the absence of ABA, with the silencing of SnRK2 output and the preparation of the new state of $\mathrm{ABA}$ response.

\section{OTHER IMPLICATIONS OF CK2 ACTION IN ABA SIGNALING}

One particularly important process in the regulation of plantwater relationship is the incorporation of circadian responses in the output of the ABA signal. In fact, the regulation of circadian rhythms to anticipate daily and seasonal environmental cycles allows the plant to optimally incorporate external conditions into internal processes. Stomata, for instance, are able to anticipate the dawn and dusk signals, and are more responsive to ABA in the afternoon, coinciding with the timing of $\left(\mathrm{Ca}^{2+}\right)$ peak oscillations (Seo and Mas, 2015).

Circadian rhythms are autoregulatory, endogenous rhythms with a period of approximately $24 \mathrm{~h}$. In Arabidopsis, the core circadian clock is made up of genes that interact through a series of transcriptional and post-transcriptional feedback loops to create rhythmic gene expression (Seo et al., 2012; Bendix et al., 2015). Briefly, the core circadian clock consists of a negative feedback loop between the two homologous MYBlike transcription factors CIRCADIAN CLOCK ASSOCIATED 1 (CCA1) and LATE ELONGATED HYPOCOTYL (LHY) on one hand and TIMING OF CAB EXPRESSION1 (TOC1) on the other (Fogelmark and Troein, 2014).

TOC1 and ABA work antagonistically to achieve the optimal response to water status. $\mathrm{ABA}$ treatment induces $\mathrm{TOC} 1$ expression and, in a feedback loop, TOC1 attenuates ABA signaling and negatively regulates the expression of $\mathrm{ABA}$ signaling genes. TOC1 mis-expressing plants have defects in ABAdependent stomata closure and altered tolerance to drought stress 


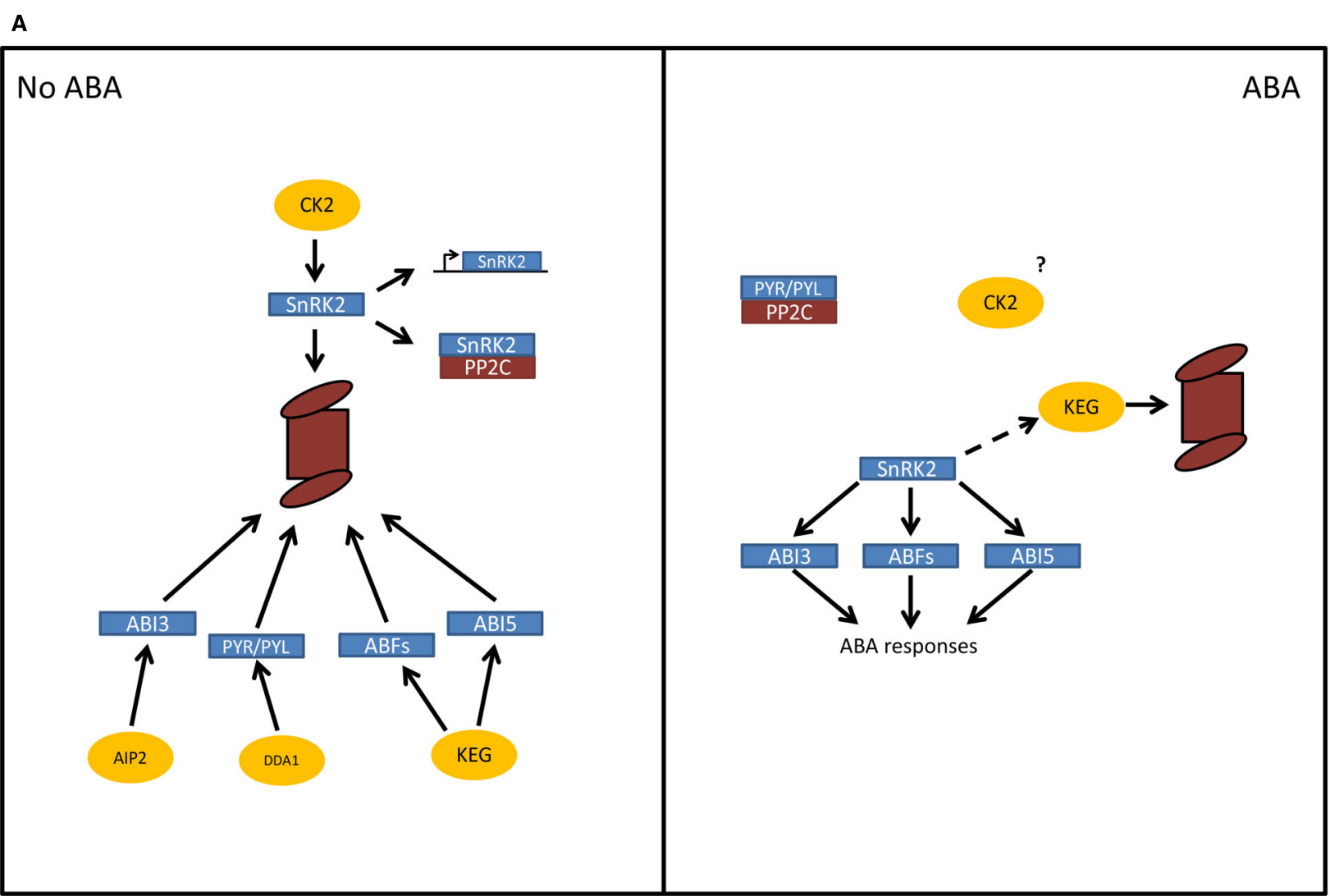

B

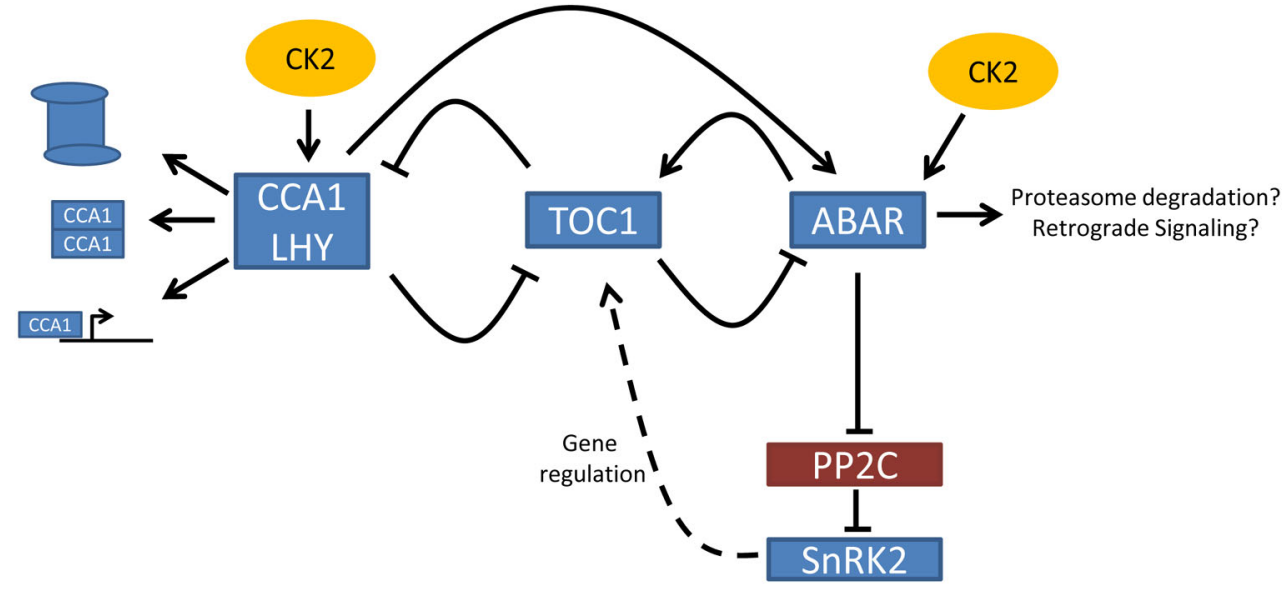

FIGURE 1 | (A) Regulation of ABA signaling by the control of protein turnover. In the absence of ABA, major regulators of the hormone such as the PYR/PYL/RCAR receptors, the SnRK2 kinases, and several transcription factors (ABI3, ABI5, ABF1, ABF3) are degraded by the proteasome, and/or inactivated. In this way the output of the ABA signal is thoroughly dampened in the absence of the hormone. When ABA levels rise, these major regulators are protected from degradation through the inactivation or degradation of the negative regulators such as KEG. CK2 is known to mediate the stabilization and destabilization of proteins in other systems and is a likely candidate to also have a role as a housekeeping kinase controlling protein turnover in ABA signaling. (B) Integration of the plant circadian clock on ABA signaling. The core circadian clock consists of a negative feedback loop between the CCA1 and LHY on one hand and TOC1 on the other. ABA treatment induces TOC1 expression and, in another feedback loop, TOC1 attenuates ABA signaling and negatively regulates the expression of ABA signaling genes like ABAR, known to interact with the ABA central signaling complex. CCA1 an LHY act synergistic to ABA and antagonistic to TOC1 expression. CCA1 and LHY are phosphorylated by CK2 targeting them for degradation, promoting CCA1 dimerization, CCA1-DNA complex formation, and interaction with the promoters of downstream genes. ABAR is also a substrate of CK2 and, even though the effects of this activity are still unknown, they could include protein turnover and altered gene expression by retrograde signaling from the chloroplast. 
(Legnaioli et al., 2009). Consequently, CCA1 an LHY should be synergistic to $\mathrm{ABA}$ and antagonistic to $\mathrm{TOC} 1$ expression (Pokhilko et al., 2013). Interestingly, one of the ABA genes negatively regulated by TOC1 is the magnesium quelatase subunit $\mathrm{H}$ (ABAR/CHLH/GUN5). ABAR is involved in retrograde signaling and positively regulates guard cell signaling in response to ABA. It has been recently demonstrated that ABAR and OST1 can interact in vitro, but that ABAR phosphorylation is independent of OST1 since it apparently acts upstream of the PP2C-SnRK2 complex (Liang et al., 2015). It should be noted that ABAR has been suggested as a potential substrate of cpCK2 (Reiland et al., 2009; Schonberg et al., 2014) but additional experiments are required to elucidate the effect of CK2 activity on this protein.

The phosphorylation of clock proteins plays a critical role in generating proper circadian rhythms (Lu et al., 2011). Overexpression of CK2 regulatory subunits (CKB3 or CKB4) in Arabidopsis displays increased CK2 activity, a reduction of the subjective day length inducing alterations in clockregulated gene expression, hypocotyl elongation, and flowering time (Sugano et al., 1999; Perales et al., 2006). CCA1 and LHY are phosphorylated by $\mathrm{CK} 2$ and this phosphorylation is required for the normal functioning of the CCA1 protein (Daniel et al., 2004). CK2 is involved in the temporal regulation of CCA1 protein activity, targeting it for degradation, promoting CCA1 dimerization, CCA1-DNA complex formation, and interaction with the promoters of downstream genes, such as TOC1 (Kusakina and Dodd, 2012).

Thus, increasing levels of ABA lead to an increase in TOC1 levels, resulting in the repression of the ABA signal through the down-regulation of ABAR/CHLH/GUN5 and CCA1 by TOC1. Concomitantly, CK2 activity would regulate the level of CCA1 repression through its controlled degradation, and regulation of protein and DNA interaction, in a process analogous to the SnRK2 repression explained earlier (Figure 1B).

\section{CONCLUDING REMARKS}

Our understanding of ABA signaling has expanded exponentially in recent years. Two seminal works on a family of soluble proteins that are able to bind $\mathrm{ABA}$ made possible the construction of a functional model for ABA signal transduction (Ma et al., 2009; Park et al., 2009). These ABA receptors (PYR/PYL/RCAR), together with SnRK2 kinases and PP2C phosphatases constitute the central core of ABA signaling.

The central core of ABA signaling controls a fast cellular response to $\mathrm{ABA}$ that ranges from activation of ion transports to a large transcription reprogramming. Nevertheless, there is

\section{REFERENCES}

Agne, B., Andres, C., Montandon, C., Christ, B., Ertan, A., Jung, F., et al. (2010). The acidic a-domain of Arabidopsis toc159 occurs as a hyperphosphorylated protein. Plant Physiol. 153, 1016-1030. doi: 10.1104/pp.110.158048

Alsheikh, M. K., Heyen, B. J., and Randall, S. K. (2003). Ion binding properties of the dehydrin ERD14 are dependent upon phosphorylation. J. Biol. Chem. 278, 40882-40889. doi: 10.1074/jbc.M307151200

Antoni, R., Rodriguez, L., Gonzalez-Guzman, M., Pizzio, G. A., and Rodriguez, P. L. (2011). News on ABA transport, protein degradation, and ABFs/WRKYs growing evidence that, following the initial response to $\mathrm{ABA}$, the persistence of the signal results in a secondary response that leads to stress adaptation. ABA signaling is also capable of incorporating several other processes, such as circadian rhythms, in their output.

Protein phosphorylation and dephosphorylation play a central role in ABA signaling and promote the activation, deactivation, sequestration and degradation of a wide range of protein regulators. In addition to protein phosphorylation, regulation of protein stability by the $26 \mathrm{~S}$ proteasome is an important mechanism for ABA signaling.

ABA signaling appears to undergo dynamic changes in the steady state of some of its major components (Figure 1). In the absence of the hormone, the PYR/PYL/RCAR receptors, the SnRK2 kinases, and several transcription factors that elicit ABA response are degraded by the proteasome, and/or inactivated. This results in an effective dampening of the ABA signal. Conversely, $\mathrm{ABA}$ has a protecting effect on the protein turnover of these components and their activation. At the same time, $\mathrm{ABA}$ transcriptionally regulates the future changes in the ABA signal.

CK2 mediated stabilization and destabilization of proteins represents a known evolutionarily conserved mechanism. Phosphorylation by $\mathrm{CK} 2$ enhances the polyubiquitination of target proteins, signaling to or protecting from proteasomal degradation. For instance, CK2 phosphorylation regulates photomorphogenesis stabilizing HY5 and HR1 and promoting degradation of PIF1 (Hardtke et al., 2000; Park et al., 2008; Bu et al., 2011). In addition, CK2 does not appear to be under major transcriptional regulation and the holoenzyme activity appears to always be in an "on" state. These characteristics make CK2 a housekeeping kinase that can modify protein functions and protein turnover in a dynamic way. In the context of ABA signaling, CK2 is already known to promote SnRK2 degradation through the $26 \mathrm{~S}$ proteasome and inactivation through the interaction with $\mathrm{PP} 2 \mathrm{C}$, and has been connected with ABAR phosphorylation. Exploring the effects of CK2 in the phosphorylation and ubiquitination of other $\mathrm{ABA}$ regulators should help to give a broader perspective on ABA signal, protein stability and integration of other processes in abiotic stress responses.

\section{FUNDING}

This work was supported by grant BIO2012-31860 (MICINN, Spain) to MP.

\section{ACKNOWLEDGMENT}

We thank Dr. D. Ludevid for critical reading of this manuscript.

in ABA signaling. Curr. Opin. Plant Biol. 14, 547-553. doi: 10.1016/j.pbi.2011. 06.004

Bailey-Serres, J., Vangala, S., Szick, K., and Lee, C. H. (1997). Acidic phosphoprotein complex of the $60 \mathrm{~S}$ ribosomal subunit of maize seedling roots. Components and changes in response to flooding. Plant Physiol. 114, 1293-1305. doi: 10.1104/pp.114.4.1293

Baldan, B., Navazio, L., Friso, A., Mariani, P., and Meggio, F. (1996). Plant calreticulin is specifically and efficiently phosphorylated by protein kinase CK2. Biochem. Biophys. Res. Commun. 221, 498-502. doi: 10.1006/bbrc.1996. 0625 
Bendix, C., Marshall, C. M., and Harmon, F. G. (2015). Circadian clock genes universally control key agricultural traits. Mol. Plant 8, 1135-1152. doi: 10.1016/j.molp.2015.03.003

Bian, Y., Ye, M., Wang, C., Cheng, K., Song, C., Dong, M., et al. (2013). Global screening of CK2 kinase substrates by an integrated phosphoproteomics workflow. Sci. Rep. 3, 3460. doi: 10.1038/srep03460

Boudsocq, M., and Sheen, J. (2013). CDPKs in immune and stress signaling. Trends Plant Sci. 18, 30-40. doi: 10.1016/j.tplants.2012.08.008

Bueso, E., Rodriguez, L., Lorenzo-Orts, L., Gonzalez-Guzman, M., Sayas, E., Munoz-Bertomeu, J., et al. (2014). The single-subunit RING-type E3 ubiquitin ligase RSL1 targets PYL4 and PYR1 ABA receptors in plasma membrane to modulate abscisic acid signaling. Plant J. 80, 1057-1071. doi: 10.1111/tpj. 12708

Bu, Q., Zhu, L., Dennis, M. D., Yu, L., Lu, S. X., Person, M. D., et al. (2011). Phosphorylation by CK2 enhances the rapid light-induced degradation of phytochrome interacting factor 1 in Arabidopsis. J. Biol. Chem. 286, 12066-12074. doi: 10.1074/jbc.M110.186882

Chen, Y. T., Liu, H., Stone, S., and Callis, J. (2013). ABA and the ubiquitin E3 ligase KEEP ON GOING affect proteolysis of the Arabidopsis thaliana transcription factors ABF1 and ABF3. Plant J. 75, 965-976. doi: 10.1111/tpj.12259

Cheong, Y. H., Pandey, G. K., Grant, J. J., Batistic, O., Li, L., Kim, B. G., et al. (2007). Two calcineurin B-like calcium sensors, interacting with protein kinase CIPK23, regulate leaf transpiration and root potassium uptake in Arabidopsis. Plant J. 52, 223-239. doi: 10.1111/j.1365-313X.2007.03236.x

Ciceri, P., Gianazza, E., Lazzari, B., Lippoli, G., Genga, A., Hoschek, G., et al. (1997). Phosphorylation of Opaque 2 changes diurnally and impacts its DNA binding activity. Plant Cell 9, 97-108. doi: 10.1105/tpc.9.1.97

Cutler, S. R., Rodriguez, P. L., Finkelstein, R. R., and Abrams, S. R. (2010). Abscisic acid: emergence of a core signaling network. Annu. Rev. Plant Biol. 61, 651-679. doi: 10.1146/annurev-arplant-042809-112122

Daniel, X., Sugano, S., and Tobin, E. M. (2004). CK2 phosphorylation of CCA1 is necessary for its circadian oscillator function in Arabidopsis. Proc. Natl. Acad. Sci. U.S.A. 101, 3292-3297. doi: 10.1073/pnas.0400163101

Danquah, A., de Zelicourt, A., Boudsocq, M., Neubauer, J., Frei Dit Frey, N., Leonhardt, N., et al. (2015). Identification and characterization of an ABAactivated MAP kinase cascade in Arabidopsis thaliana. Plant J. 82, 232-244. doi: $10.1111 /$ tpj. 12808

Datta, N., and Cashmore, A. R. (1989). Binding of a pea nuclear-protein to promoters of certain photoregulated genes is modulated by phosphorylation. Plant Cell 1, 1069-1077. doi: 10.1105/tpc.1.11.1069

de Cárcer, G., Cerdido, A., and Medina, F. J. (1997). NopA64, a novel nucleolar phosphoprotein from proliferating onion cells, sharing immunological determinants with mammalian nucleolin. Planta 201, 487-495. doi: $10.1007 / \mathrm{s} 004250050093$

Dennis, M. D., and Browning, K. S. (2009). Differential phosphorylation of plant translation initiation factors by Arabidopsis thaliana CK2 holoenzymes. J. Biol. Chem. 284, 20602-20614. doi: 10.1074/jbc.M109.006692

Finkelstein, R., Gampala, S. S., Lynch, T. J., Thomas, T. L., and Rock, C. D. (2005). Redundant and distinct functions of the ABA response loci ABAINSENSITIVE(ABI)5 and ABRE-BINDING FACTOR (ABF)3. Plant Mol. Biol. 59, 253-267. doi: 10.1007/s11103-005-8767-2

Finkelstein, R., Lynch, T., Reeves, W., Petitfils, M., and Mostachetti, M. (2011). Accumulation of the transcription factor ABA-insensitive (ABI)4 is tightly regulated post-transcriptionally. J. Exp. Bot. 62, 3971-3979. doi: $10.1093 /$ jxb/err093

Finkelstein, R. R., Gampala, S. S. L., and Rock, C. D. (2002). Abscisic Acid Signaling in Seeds and Seedlings. Plant Cell 14, S15-S45.

Finkelstein, R. R., and Lynch, T. J. (2000). The Arabidopsis abscisic acid response gene ABI5 encodes a basic leucine zipper transcription factor. Plant Cell 12, 599-609. doi: $10.1105 /$ tpc.12.4.599

Fogelmark, K., and Troein, C. (2014). Rethinking transcriptional activation in the Arabidopsis circadian clock. PLoS Comput. Biol. 10:e1003705. doi: 10.1371/journal.pcbi.1003705

Fujii, H., Chinnusamy, V., Rodrigues, A., Rubio, S., Antoni, R., Park, S. Y., et al. (2009). In vitro reconstitution of an abscisic acid signalling pathway. Nature 462, 660-664. doi: 10.1038/nature08599

Galau, G., Hughes, D. W., and Dure, L., and III. (1986). Abscisic acid induction of cloned cotton late embryogenesis-abundant (Lea) mRNAs. Plant Mol. Biol. 7, 155-170. doi: 10.1007/bf00021327
Godoy, J., Lunar, R., Torres-Schumann, S., Moreno, J., Rodrigo, R., and PintorToro, J. (1994). Expression, tissue distribution and subcellular localization of dehydrin TAS14 in salt-stressed tomato plants. Plant Mol. Biol. 26, 1921-1934. doi: 10.1007/BF00019503

Gregorio, J., Hernandez-Bernal, A. F., Cordoba, E., and Leon, P. (2014). Characterization of evolutionarily conserved motifs involved in activity and regulation of the ABA-INSENSITIVE (ABI) 4 transcription factor. Mol. Plant 7, 422-436. doi: $10.1093 / \mathrm{mp} / \mathrm{sst} 132$

Hardtke, C. S., Gohda, K., Osterlund, M. T., Oyama, T., Okada, K., and Deng, X. W. (2000). HY5 stability and activity in Arabidopsis is regulated by phosphorylation in its COP1 binding domain. EMBO J. 19, 4997-5006. doi: 10.1093/emboj/19.18.4997

Himmelbach, A., Hoffmann, T., Leube, M., Höhener, B., and Grill, E. (2002). Homeodomain protein ATHB6 is a target of the protein phosphatase ABI1 and regulates hormone responses in Arabidopsis. EMBO J. 21, 3029-3038. doi: $10.1093 / \mathrm{emboj} / \mathrm{cdf} 316$

Hong, J. Y., Chae, M. J., Lee, I. S., Lee, Y. N., Nam, M. H., Kim, D. Y., et al. (2011). Phosphorylation-mediated regulation of a rice ABA responsive element binding factor. Phytochemistry 72, 27-36. doi: 10.1016/j.phytochem.2010. 10.005

Hsieh, H. L., Song, C. J., and Roux, S. J. (2000). Regulation of a recombinant pea nuclear apyrase by calmodulin and casein kinase II. Biochim. Biophys. Acta 1494, 248-255. doi: 10.1016/s0167-4781(00)00245-1

Ingram, J., and Bartels, D. (1996). The molecular basis of dehydration tolerance in plants. Annu. Rev. Plant Physiol. Plant Mol. Biol. 47, 377-403. doi: 10.1146/annurev.arplant.47.1.377

Irigoyen, M. L., Iniesto, E., Rodriguez, L., Puga, M. I., Yanagawa, Y., Pick, E., et al. (2014). Targeted degradation of abscisic acid receptors is mediated by the ubiquitin ligase substrate adaptor DDA1 in Arabidopsis. Plant Cell 26, 712-728. doi: $10.1105 /$ tpc.113.122234

Kanekatsu, M., Ezumi, A., Nakamura, T., and Ohtsuki, K. (1995). Chloroplast ribonucleoproteins (RNPs) as phosphate acceptors for casein kinase II: purification by ssDNA-cellulose column chromatography. Plant Cell Physiol. 36, 1649-1656

Kanekatsu, M., Munakata, H., Furuzono, K., and Ohtsuki, K. (1993). Biochemical characterization of a $34 \mathrm{kda}$ ribonucleoprotein (p34) purified from the spinach chloroplast fraction as an effective phosphate acceptor for casein kinase II. FEBS Lett. 335, 176-180. doi: 10.1016/0014-5793(93)80724-9

Kanekatsu, M., Saito, H., Motohashi, K., and Hisabori, T. (1998). The beta subunit of chloroplast ATP synthase (CFOCF1-ATPase) is phosphorylated by casein kinase II. Biochem. Mol. Biol. Int. 46, 99-105.

Kang, H. G., and Klessig, D. F. (2005). Salicylic acid-inducible Arabidopsis CK2-like activity phosphorylates TGA2. Plant Mol. Biol. 57, 541-557. doi: 10.1007/s11103-005-0409-1

Kim, T.-H., Böhmer, M., Hu, H., Nishimura, N., and Schroeder, J. I. (2010). Guard cell signal transduction network: advances in understanding abscisic acid, $\mathrm{CO}_{2}$, and $\mathrm{Ca}^{2+}$ Signaling. Annu. Rev. Plant Biol. 61, 561-591. doi: 10.1146/annurevarplant-042809-112226

Klimczak, L. J., Collinge, M. A., Farini, D., Giuliano, G., Walker, J. C., and Cashmore, A. R. (1995). Reconstitution of Arabidopsis casein kinase II from recombinant subunits and phosphorylation of transcription factor GBF1. Plant Cell 7, 105-115. doi: 10.1105/tpc.7.1.105

Klingler, J. P., Batelli, G., and Zhu, J. K. (2010). ABA receptors: the START of a new paradigm in phytohormone signalling. J. Exp. Bot. 61, 3199-3210. doi: $10.1093 /$ jxb/erq151

Krohn, N. M., Stemmer, C., Fojan, P., Grimm, R., and Grasser, K. D. (2003). Protein kinase CK2 phosphorylates the high mobility group domain protein SSRP1, inducing the recognition of UV-damaged DNA. J. Biol. Chem. 278, 12710-12715. doi: 10.1074/jbc.M300250200

Kusakina, J., and Dodd, A. N. (2012). Phosphorylation in the plant circadian system. Trends Plant Sci. 17, 575-583. doi: 10.1016/j.tplants.2012.06.008

Lechner, E., Leonhardt, N., Eisler, H., Parmentier, Y., Alioua, M., Jacquet, H., et al. (2011). MATH/BTB CRL3 receptors target the homeodomain-leucine zipper ATHB6 to modulate abscisic acid signaling. Dev. Cell 21, 1116-1128. doi: 10.1016/j.devcel.2011.10.018

Lee, Y., Lloyd, A. M., and Roux, S. J. (1999). Antisense Expression of the CK2 alpha -Subunit Gene in Arabidopsis. effects on light-regulated gene expression and plant growth. Plant Physiol. 119, 989-1000. doi: 10.1104/pp.119. 3.989 
Legnaioli, T., Cuevas, J., and Mas, P. (2009). TOC1 functions as a molecular switch connecting the circadian clock with plant responses to drought. EMBO J. 28, 3745-3757. doi: 10.1038/emboj.2009.297

León, P., Gregorio, J., and Cordoba, E. (2012). ABI4 and its role in chloroplast retrograde communication. Front. Plant Sci. 3:304. doi: 10.3389/fpls.2012.00304

Leung, J., and Giraudat, J. (1998). ABSCISIC ACID SIGNAL TRANSDUCTION. Annu. Rev. Plant Physiol. Plant Mol. Biol. 49, 199-222. doi: 10.1146/annurev.arplant.49.1.199

Li, H., and Roux, S. J. (1992). Casein kinase II protein kinase is bound to laminamatrix and phosphorylates lamin-like protein in isolated pea nuclei. Proc. Natl. Acad. Sci. U.S.A. 89, 8434-8438.

Liang, S., Lu, K., Wu, Z., Jiang, S.-C., Yu, Y.-T., Bi, C., et al. (2015). A link between magnesium-chelatase $\mathrm{H}$ subunit and sucrose non-fermenting 1 (SNF1)-related protein kinase SnRK2.6/OST1 in Arabidopsis guard cell signalling in response to abscisic acid. J. Exp. Bot. 66, 6355-6369. doi: 10.1093/jxb/erv341

Lisitsky, I., and Schuster, G. (1995). Phosphorylation of a chloroplast rna-binding protein-changes its affinity to rna. Nucleic Acids Res. 23, 2506-2511. doi: $10.1093 /$ nar/23.13.2506

Litchfield, D. W. (2003). Protein kinase CK2: structure, regulation and role in cellular decisions of life and death. Biochem. J. 369, 1-15. doi: 10.1042/bj20021469

Liu, H., and Stone, S. L. (2010). Abscisic acid increases Arabidopsis ABI5 transcription factor levels by promoting KEG E3 ligase self-ubiquitination and proteasomal degradation. Plant Cell 22, 2630-2641. doi: 10.1105/tpc.110. 076075

Liu, H., and Stone, S. L. (2013). Cytoplasmic degradation of the Arabidopsis transcription factor abscisic acid insensitive 5 is mediated by the RINGtype E3 ligase KEEP ON GOING. J. Biol. Chem. 288, 20267-20279. doi: 10.1074/jbc.M113.465369

Liu, Y., Wang, L., Jiang, S., Pan, J., Cai, G., and Li, D. (2014). Group 5 LEA protein, ZmLEA5C, enhance tolerance to osmotic and low temperature stresses in transgenic tobacco and yeast. Plant Physiol. Biochem. 84, 22-31. doi: 10.1016/j.plaphy.2014.08.016

Lopez-Molina, L., Mongrand, S., and Chua, N. H. (2001). A postgermination developmental arrest checkpoint is mediated by abscisic acid and requires the ABI5 transcription factor in Arabidopsis. Proc. Natl. Acad. Sci. U.S.A. 98, 4782-4787. doi: 10.1073/pnas.081594298

Lopez-Molina, L., Mongrand, S., Kinoshita, N., and Chua, N. H. (2003). AFP is a novel negative regulator of $\mathrm{ABA}$ signaling that promotes $\mathrm{ABI} 5$ protein degradation. Genes Dev. 17, 410-418. doi: 10.1101/gad.1055803

Lu, S. X., Liu, H., Knowles, S. M., Li, J., Ma, L., Tobin, E. M., et al. (2011). A role for protein kinase casein kinase2 alpha-subunits in the Arabidopsis circadian clock. Plant Physiol. 157, 1537-1545. doi: 10.1104/pp.111.179846

Lyzenga, W. J., Liu, H., Schofield, A., Muise-Hennessey, A., and Stone, S. L. (2013). Arabidopsis CIPK26 interacts with KEG, components of the ABA signalling network and is degraded by the ubiquitin-proteasome system. J. Exp. Bot. 64, 2779-2791. doi: 10.1093/jxb/ert123

Lyzenga, W. J., and Stone, S. L. (2012). Abiotic stress tolerance mediated by protein ubiquitination. J. Exp. Bot. 63, 599-616. doi: 10.1093/jxb/err310

Marquès-Bueno, M. M., Moreno-Romero, J., Abas, L., De Michele, R., and Martínez, M. C. (2011). A dominant negative mutant of protein kinase CK2 exhibits altered auxin responses in Arabidopsis. Plant J. 67, 169-180. doi: 10.1111/j.1365313X.2011.04585.x

Ma, Y., Szostkiewicz, I., Korte, A., Moes, D., Yang, Y., Christmann, A., et al. (2009). Regulators of PP2C phosphatase activity function as abscisic acid sensors. Science 324, 1064-1068. doi: 10.1126/science.1172408

Meggio, F., and Pinna, L. A. (2003). One-thousand-and-one substrates of protein kinase CK2? FASEB J. 17, 349-368. doi: 10.1096/fj.02-0473rev

Meier, I., Phelan, T., Gruissem, W., Spiker, S., and Schneider, D. (1996). MFP1, a novel plant filament-like protein with affinity for matrix attachment region DNA. Plant Cell 8, 2105-2115. doi: 10.1105/tpc.8.11.2105

Miura, K., Lee, J., Jin, J. B., Yoo, C. Y., Miura, T., and Hasegawa, P. M. (2009). Sumoylation of ABI5 by the Arabidopsis SUMO E3 ligase SIZ1 negatively regulates abscisic acid signaling. Proc. Natl. Acad. Sci. U.S.A. 106, 5418-5423. doi: 10.1073/pnas.0811088106

Moreno-Romero, J., Espunya, M. C., Platara, M., Arino, J., and Martinez, M. C. (2008). A role for protein kinase CK2 in plant development: evidence obtained using a dominant-negative mutant. Plant J. 55, 118-130. doi: 10.1111/j.1365313X.2008.03494.x
Mori, I. C., Murata, Y., Yang, Y., Munemasa, S., Wang, Y. F., Andreoli, S., et al. (2006). CDPKs CPK6 and CPK3 function in ABA regulation of guard cell S-type anion- and $\mathrm{Ca}^{2+}$-permeable channels and stomatal closure. PLoS Biol. 4:e327. doi: 10.1371/journal.pbio.0040327

Mulekar, J., Bu, Q., Chen, F., and Huq, E. (2012). Casein kinase II alpha subunits affect multiple developmental and stress-responsive pathways in Arabidopsis. Plant J. 69, 343-354. doi: 10.1111/j.1365-313X.2011.04794.x

Mulekar, J. J., and Huq, E. (2014). Expanding roles of protein kinase CK2 in regulating plant growth and development. J. Exp. Bot. 65, 2883-2893. doi: $10.1093 /$ jxb/ert401

Mulekar, J. J., and Huq, E. (2015). Arabidopsis casein kinase $2 \alpha 4$ subunit regulates various developmental pathways in a functionally overlapping manner. Plant Sci. 236, 295-303. doi: 10.1016/j.plantsci.2015.04.013

Nieva, C., Busk, P., Domínguez-Puigjaner, E., Lumbreras, V., Testillano, P., Risueño, M.-C., et al. (2005). Isolation and functional characterisation of two new bZIP maize regulators of the ABA responsive gene rab28. Plant Mol. Biol. 58, 899-914. doi: 10.1007/s11103-005-8407-x

Ogiso, E., Takahashi, Y., Sasaki, T., Yano, M., and Izawa, T. (2010). The role of casein kinase II in flowering time regulation has diversified during evolution. Plant Physiol. 152, 808-820. doi: 10.1104/pp.109.148908

Ohtsuki, K., Nakamura, S., Shimoyama, Y., Shibata, D., Munakata, H., Yoshiki, Y., et al. (1995). A 96-KDa glycyrrhizin-binding protein (gp96) from soybeans acts as a substrate for case in kinase II, and is highly realted to lipoxygenase3. J. Biochem. (Tokio) 118, 1145-1150.

Ohtsuki, K., Ohishi, M., Karino, A., Kanekatsu, M., and Shamsa, F. (1994). Purification and characterization of 100-kDa Glycyrrhizin (GL)-Binding Protein (gp100) as an effective phosphate acceptor for CK-II and the effect of GL on the phosphorylation of gp100 by CK-II in vitro. Biochem. Biophys. Res. Commun. 198, 1090-1098. doi: 10.1006/bbrc.1994.1155

Padmanabha, R., Chen-Wu, J., Hanna, D., and Glover, C. (1990). Isolation, sequencing, and disruption of the yeast CKA2 gene: casein kinase II is essential for viability in Saccharomyces cerevisiae. Mol. Cell. Biol. 10, 4089-4099. doi: 10.1128/MCB.10.8.4089

Park, H. J., Ding, L., Dai, M., Lin, R., and Wang, H. (2008). Multisite phosphorylation of Arabidopsis HFR1 by casein kinase II and a plausible role in regulating its degradation rate. J. Biol. Chem. 283, 23264-23273. doi: 10.1074/jbc.M801720200

Park, S. Y., Fung, P., Nishimura, N., Jensen, D. R., Fujii, H., Zhao, Y., et al. (2009). Abscisic acid inhibits type 2C protein phosphatases via the PYR/PYL family of START proteins. Science 324, 1068-1071. doi: 10.1126/science.1173041

Park, S. Y., Peterson, F. C., Mosquna, A., Yao, J., Volkman, B. F., and Cutler, S. R. (2015). Agrochemical control of plant water use using engineered abscisic acid receptors. Nature 520, 545-548. doi: 10.1038/nature14123

Perales, M., Portolés, S., and Más, P. (2006). The proteasome-dependent degradation of CKB4 is regulated by the Arabidopsis biological clock. Plant J. 46, 849-860. doi: 10.1111/j.1365-313X.2006.02744.x

Plana, M., Itarte, E., Eritja, R., Goday, A., Pages, M., and Martinez, M. C. (1991). Phosphorylation of maize RAB-17 protein by casein kinase 2. J. Biol. Chem. 266, 22510-22514.

Pokhilko, A., Mas, P., and Millar, A. J. (2013). Modelling the widespread effects of TOC1 signalling on the plant circadian clock and its outputs. BMC Syst. Biol. 7:23. doi: 10.1186/1752-0509-7-23

Raghavendra, A. S., Gonugunta, V. K., Christmann, A., and Grill, E. (2010). ABA perception and signalling. Trends Plant Sci. 15, 395-401. doi: 10.1016/j.tplants.2010.04.006

Rahman, L. N., Smith, G. S. T., Bamm, V. V., Voyer-Grant, J. A. M., Moffatt, B. A., Dutcher, J. R., et al. (2011). Phosphorylation of Thellungiella salsuginea dehydrins TsDHN-1 and TsDHN-2 facilitates cation-induced conformational changes and actin assembly. Biochemistry 50, 9587-9604. doi: 10.1021/bi201205m

Ralet, M.-C., Fouques, D., Leonil, J., Molle, D., and Meunier, J.-C. (1999). Soybean $\beta$-conglycinin $\alpha$ subunit is phosphorylated on two distinct serines by protein kinase CK2. J. Protein Chem. 18, 315-323. doi: 10.1023/a:1021091413084

Reiland, S., Messerli, G., Baerenfaller, K., Gerrits, B., Endler, A., Grossmann, J., et al. (2009). Large-scale Arabidopsis phosphoproteome profiling reveals novel chloroplast kinase substrates and phosphorylation networks. Plant Physiol. 150, 889-903. doi: 10.1104/pp.109.138677

Riera, M., Figueras, M., Lopez, C., Goday, A., and Pages, M. (2004). Protein kinase CK2 modulates developmental functions of the abscisic acid responsive 
protein Rab17 from maize. Proc. Natl. Acad. Sci. U.S.A. 101, 9879-9884. doi: 10.1073/pnas.0306154101

Riera, M., Vélez-Bermudez, I. C., Legnaioli, T., and Pagès, M. (2013). "Specific features of plant CK2," in Protein Kinase CK2, ed. L. Pinna (Wiley-Blackwell), 267-279. doi: 10.1002/9781118482490.ch9

Samaniego, R., Jeong, S. Y., de la Torre, C., Meier, I., and Moreno Diaz de la Espina, S. (2006). CK2 phosphorylation weakens $90 \mathrm{kDa}$ MFP1 association to the nuclear matrix in Allium cepa. J. Exp. Bot. 57, 113-124. doi: 10.1093/jxb/erj010

Schonberg, A., Bergner, E., Helm, S., Agne, B., Dunschede, B., Schunemann, D., et al. (2014). The peptide microarray "ChloroPhos1.0" identifies new phosphorylation targets of plastid casein kinase II (pCKII) in Arabidopsis thaliana. PLoS ONE 9:e108344. doi: 10.1371/journal.pone.0108344

Schroeder, J. I., Kwak, J. M., and Allen, G. J. (2001). Guard cell abscisic acid signalling and engineering drought hardiness in plants. Nature 410, 327-330. doi: $10.1038 / 35066500$

Schweer, J., Turkeri, H., Link, B., and Link, G. (2010). AtSIG6, a plastid sigma factor from Arabidopsis, reveals functional impact of cpCK2 phosphorylation. Plant J. 62, 192-202. doi: 10.1111/j.1365-313X.2010.04138.x

Seo, K. I., Lee, J. H., Nezames, C. D., Zhong, S., Song, E., Byun, M. O., et al. (2014). ABD1 is an Arabidopsis DCAF substrate receptor for CUL4-DDB1-based E3 ligases that acts as a negative regulator of abscisic acid signaling. Plant Cell 26, 695-711. doi: 10.1105/tpc.113.119974

Seo, P. J., and Mas, P. (2015). STRESSing the role of the plant circadian clock. Trends Plant Sci. 20, 230-237. doi: 10.1016/j.tplants.2015.01.001

Seo, P. J., Park, M. J., Lim, M. H., Kim, S. G., Lee, M., Baldwin, I. T., et al. (2012). A self-regulatory circuit of CIRCADIAN CLOCK-ASSOCIATED1 underlies the circadian clock regulation of temperature responses in Arabidopsis. Plant Cell 24, 2427-2442. doi: 10.1105/tpc.112.098723

Sirichandra, C., Davanture, M., Turk, B. E., Zivy, M., Valot, B., Leung, J., et al. (2010). The Arabidopsis ABA-activated kinase OST1 phosphorylates the bZIP transcription factor ABF3 and creates a 14-3-3 binding site involved in its turnover. PLoS ONE 5:e13935. doi: 10.1371/journal.pone.0013935

Stemmer, C., Schwander, A., Bauw, G., Fojan, P., and Grasser, K. D. (2002). Protein kinase CK2 differentially phosphorylates maize chromosomal high mobility group B (HMGB) proteins modulating their stability and DNA interactions. J. Biol. Chem. 277, 1092-1098. doi: 10.1074/jbc.M109503200

Sugano, S., Andronis, C., Green, R. M., Wang, Z. Y., and Tobin, E. M. (1998). Protein kinase CK2 interacts with and phosphorylates the Arabidopsis circadian clock-associated 1 protein. Proc. Natl. Acad. Sci. U.S.A. 95, 11020-11025.

Sugano, S., Andronis, C., Ong, M. S., Green, R. M., and Tobin, E. M. (1999). The protein kinase CK2 is involved in regulation of circadian rhythms in Arabidopsis. Proc. Nat. Acad. Sci. U.S.A. 96, 12362-12366. doi: 10.1073/pnas.96.22.12362

Testi, M. G., Croce, R., Laureto, P. P.-D., and Bassi, R. (1996). A CK2 site is reversibly phosphorylated in the photosystem II subunit CP29. FEBS Lett. 399, 245-250. doi: 10.1016/s0014-5793(96)01333-6

Tjaden, G., and Coruzzi, G. (1994). A novel AT-rich DNA binding protein that combines an HMG-like DNA binding protein with a putative transcription domain. Plant Cell 6, 107-118. doi: 10.1105/tpc.6.1.107

Tosoni, K., Costa, A., Sarno, S., D’Alessandro, S., Sparla, F., Pinna, L. A., et al. (2011). The p23 co-chaperone protein is a novel substrate of CK2 in Arabidopsis. Mol. Cell. Biochem. 356, 245-254. doi: 10.1007/s11010-011-0969-0

Turkeri, H., Schweer, J., and Link, G. (2012). Phylogenetic and functional features of the plastid transcription kinase cpCK2 from Arabidopsis signify a role of cysteinyl SH-groups in regulatory phosphorylation of plastid sigma factors. FEBS J. 279, 395-409. doi: 10.1111/j.1742-4658.2011.08433.x

Tuteja, N., Beven, A. F., Shaw, P. J., and Tuteja, R. (2001). A pea homologue of human DNA helicase I is localized within the dense fibrillar component of the nucleolus and stimulated by phosphorylation with CK2 and cdc2 protein kinases. Plant J. 25, 9-17. doi: 10.1111/j.1365-313X.2001. 00918.x

Tuteja, N., Reddy, M. K., Mudgil, Y., Yadav, B. S., Chandok, M. R., and Sopory, S. K. (2003). Pea DNA topoisomerase I is phosphorylated and stimulated by casein kinase 2 and protein kinase C. Plant Physiol. 132, 2108-2115. doi: $10.1104 /$ pp. 103.024273

Umeda, M., Manabe, Y., and Uchimiya, H. (1997). Phosphorylation of the C2 subunit of the proteasome in rice (Oryza sativa L.). FEBS Lett. 403, 313-317. doi: 10.1016/s0014-5793(97)00073-2

Umezawa, T., Nakashima, K., Miyakawa, T., Kuromori, T., Tanokura, M., Shinozaki, K., et al. (2010). Molecular basis of the core regulatory network in ABA responses: sensing, signaling and transport. Plant Cell Physiol. 51, 1821-1839. doi: $10.1093 / \mathrm{pcp} / \mathrm{pcq} 156$

Vélez-Bermúdez, I. C., Carretero-Paulet, L., Legnaioli, T., Ludevid, D., Pagès, M., and Riera, M. (2015). Novel CK2 $\alpha$ and CK2 $\beta$ subunits in maize reveal functional diversification in subcellular localization and interaction capacity. Plant Sci. 235, 58-69. doi: 10.1016/j.plantsci.2015.03.005

Velez-Bermudez, I., Irar, S., Carretero-Paulet, L., Pagès, M., and Riera, M. (2011). Specific characteristics of CK2B regulatory subunits in plants. Mol. Cell. Biochem. 356, 255-260. doi: 10.1007/s11010-011-0971-6

Vilela, B., Najar, E., Lumbreras, V., Leung, J., and Pages, M. (2015). Casein kinase 2 negatively regulates abscisic acid-activated SnRK2s in the core abscisic acid-signaling module. Mol. Plant 8, 709-721. doi: 10.1016/j.molp.2014. 12.012

Wang, H.-C., Wu, J.-S., Chia, J.-C., Yang, C.-C., Wu, Y.-J., and Juang, R.-H. (2009). Phytochelatin synthase is regulated by protein phosphorylation at a threonine residue near its catalytic site. J. Agric. Food Chem. 57, 7348-7355. doi: 10.1021/jf9020152

Wang, Y., Chang, H., Hu, S., Lu, X., Yuan, C., Zhang, C., et al. (2014). Plastid casein kinase 2 knockout reduces abscisic acid (ABA) sensitivity, thermotolerance, and expression of ABA- and heat-stress-responsive nuclear genes. J. Exp. Bot. 65, 4159-4175. doi: 10.1093/jxb/eru190

Yamburenko, M. V., Zubo, Y. O., and Börner, T. (2015). Abscisic acid affects transcription of chloroplast genes via protein phosphatase $2 \mathrm{C}$-dependent activation of nuclear genes: repression by guanosine $-3^{\prime}-5^{\prime}$-bisdiphosphate and activation by sigma factor 5. Plant J. 82, 1030-1041. doi: 10.1111/tpj.12876

Yamburenko, M. V., Zubo, Y. O., Vanková, R., Kusnetsov, V. V., Kulaeva, O. N., and Börner, T. (2013). Abscisic acid represses the transcription of chloroplast genes. J. Exp. Bot. 64, 4491-4502. doi: 10.1093/jxb/ert258

Zhang, X., Garreton, V., and Chua, N. H. (2005). The AIP2 E3 ligase acts as a novel negative regulator of ABA signaling by promoting ABI3 degradation. Genes Dev 19, 1532-1543. doi: 10.1101/gad.1318705

Zhang, X. L., Jiang, L., Xin, Q., Liu, Y., Tan, J. X., and Chen, Z. Z. (2015). Structural basis and functions of abscisic acid receptors PYLs. Front. Plant Sci. 6:88. doi: $10.3389 /$ fpls.2015.00088

Conflict of Interest Statement: The authors declare that the research was conducted in the absence of any commercial or financial relationships that could be construed as a potential conflict of interest.

Copyright (C) 2015 Vilela, Pagès and Riera. This is an open-access article distributed under the terms of the Creative Commons Attribution License (CC BY). The use, distribution or reproduction in other forums is permitted, provided the original author(s) or licensor are credited and that the original publication in this journal is cited, in accordance with accepted academic practice. No use, distribution or reproduction is permitted which does not comply with these terms. 